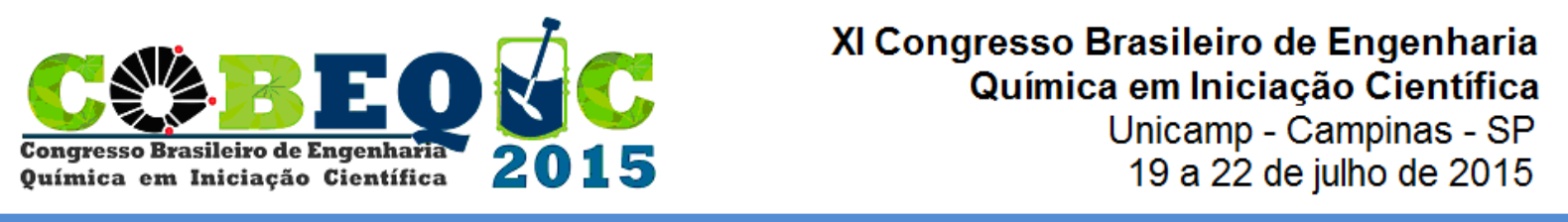

\title{
ESTUDO DA DESSORÇÃO DO CORANTE TÊXTIL REATIVO AZUL 5G ADSORVIDO EM BAGAÇO DE MALTE
}

\author{
H. H. PIFFER ${ }^{1}$, P. T. JUCHEN ${ }^{1}$, M. T. VEIT ${ }^{1}$, M. R. FAGUNDES-KLEN ${ }^{1}$, \\ S. M. PALÁCIO ${ }^{1}$, G. C. GONÇALVES ${ }^{2}$ \\ ${ }^{1}$ Universidade Estadual do Oeste do Paraná, Departamento de Engenharia Química \\ ${ }^{2}$ Universidade Tecnológica Federal do Paraná, Processos Químicos \\ E-mail para contato: handria_piffer@hotmail.com
}

\begin{abstract}
RESUMO - O objetivo deste trabalho foi estudar a eficiência de dessorção do corante reativo azul $5 \mathrm{G}$ adsorvido no bagaço de malte, um subproduto do processo de filtração da cerveja. Três agentes eluentes, um básico, um ácido e um sal foram avaliados, apresentando potencial de dessorção apenas o eluente básico $\left(\mathrm{NaOH} 1 \mathrm{~mol} \cdot \mathrm{L}^{-1}\right)$. A cinética de dessorção foi realizada em intervalos de tempos pré-estabelecidos em diferentes temperaturas $\left(30{ }^{\circ} \mathrm{C}, 40{ }^{\circ} \mathrm{C}\right.$ e $\left.50{ }^{\circ} \mathrm{C}\right)$. A cinética mostrou que a temperatura de $50{ }^{\circ} \mathrm{C}$ foi a que apresentou maior eficiência de dessorção $(70,8 \%)$ para um tempo de contato de uma hora.
\end{abstract}

\section{INTRODUÇÃO}

A indústria têxtil é uma das maiores do mundo, em termos de produção e geração de empregos, porém seus processos são grandes consumidores de água e de corantes sintéticos, geradores de efluentes (CEGARRA, 2000). A legislação nacional define um índice de coloração apenas para os corpos de água, variando conforme o tipo de água (doce, salgada ou salobra), exigindo tratamentos eficientes aos efluentes e o desenvolvimento de novas tecnologias, considerando custos, tempo e eficiência dos processos de eliminação de toxicidade, principalmente dos corantes têxteis (BUMPUS e AUST, 1987).

Industrialmente são utilizados, em média, 10.000 diferentes tipos de corantes e pigmentos (PEARCE, 2003), sendo maior a demanda por corantes ácidos e reativos (GUARATINI e ZANONI, 2000), que representam de 20 a $30 \%$ de todos os corantes utilizados (ALMEIDA, 2004).

Uma das consequências mais relevantes dos corantes é a geração de outras substâncias com propriedades carcinogênicas e mutagênicas, devido à degradação parcial e ao processo de biotransformação, os corantes podem ser catalisados por enzimas específicas ou outras reações oxidativas (GUARANTINI e ZANONI, 2000).

Um corante amplamente utilizado na indústria têxtil é o corante reativo azul $5 \mathrm{G}$, o qual apresenta solubilidade acima de 100 g.L.-1 a $25^{\circ} \mathrm{C}$, pH entre 6,0 e 9,0 (TEXPAL, 2008), massa molecular de 815 g.gmol ${ }^{-1}$.

Existem muitos métodos eficazes para o tratamento de efluentes contaminados por corantes. Royer (2008) considera a técnica de adsorção superior a outras técnicas tanto para 


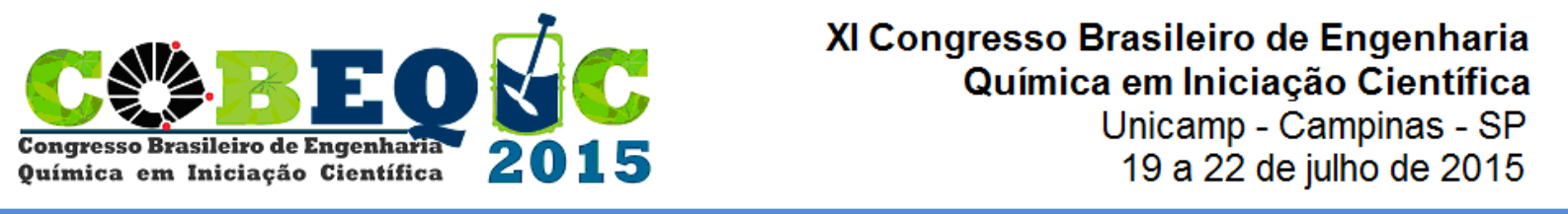

reutilização de águas como para a regeneração de muitos adsorventes após o seu uso. Esta técnica é um processo físico-químico no qual uma substância é acumulada numa interface entre fases. Quando as substâncias presentes no líquido se acumulam numa interface sólidolíquido, denomina-se adsorvato (a substância que está sendo removida da fase líquida) e adsorvente, a fase sólida. A dessorção pode ser definida como a liberação de uma substância ou material de uma interface entre uma superfície sólida e uma solução (FREITAS, 2010).

Neste trabalho será estudado o uso do bagaço de malte como adsorvente, o qual é o principal subproduto do processo cervejeiro. A cada 100 litros de cerveja produzida, são gerados cerca de 10-20 kg de bagaço de malte (SANTOS e RIBEIRO, 2005). De acordo com a Associação Brasileira da Indústria da Cerveja (CERVBRASIL, 2015), em 2014 foram produzidos 14,1 bilhões de litros de cerveja, dando ideia da quantidade de subproduto gerado.

\section{METODOLOGIA}

\subsection{Preparo da solução de corante}

As soluções utilizadas foram preparadas a partir da dissolução do corante Azul 5G reativo, fornecido pela Texpal Química, em água destilada, na concentração inicial de $500 \mathrm{mg} . \mathrm{L}^{-1}$. O pH da solução de corante foi ajustado a partir da adição de ácido clorídrico na concentração de 0,1 mol.L ${ }^{-1}$.

\subsection{Preparo do material adsorvente}

O adsorvente utilizado nos experimentos foi o bagaço de malte, um subproduto do processo de filtração da cerveja, fornecido por uma indústria cervejeira situada no Oeste do Paraná - Brasil. Para o preparo do bagaço de malte, o mesmo foi submetido à lavagem com água corrente, para a remoção das impurezas, seguido de enxágue com água destilada, e posterior secagem a $70{ }^{\circ} \mathrm{C}$. O material seco foi utilizado sem separação granulométrica, visto que estudos preliminares indicaram que o processo de separação granulométrica não se mostrou vantajoso em relação às quantidades de corante adsorvidas.

\subsection{Saturação do material adsorvente}

$\mathrm{O}$ experimento de saturação do bagaço de malte com o corante têxtil Azul $5 \mathrm{G}$ reativo foi realizado na concentração inicial da solução de corante de 454,83 mg. $\mathrm{L}^{-1}$, pH de 3 , temperatura ambiente em torno de $25-30{ }^{\circ} \mathrm{C}$, rotação de $100 \mathrm{rpm}$, volume de solução de $50 \mathrm{~mL}$ e dosagem de adsorvente de 50 g.L $\mathrm{L}^{-1}$ ( $150 \mathrm{~g}$ de bagaço em 3 litros de solução de corante). Para a saturação do adsorvente utilizou-se o agitador mecânico da marca Tecnal, modelo TE-139, na rotação aproximada de $100 \mathrm{rpm}$. Após 24 horas de contato, o adsorvente foi retirado da solução e seco a temperatura ambiente $\left(25-30^{\circ} \mathrm{C}\right)$. A medição da concentração remanescente de corante em solução foi determinada no comprimento de onda de $610 \mathrm{~nm}$ e calculada (equação (1)) a quantidade de corante adsorvida por grama de bagaço de malte ( $\mathrm{q}_{\mathrm{eq}}$, mg.g $\left.\mathrm{g}^{-1}\right)$ : 
$q_{e q}=\frac{\left(C_{0}-C\right) V}{m}$

\subsection{Determinação do agente eluente}

Analisou-se a eficiência de dessorção, equação (2), para determinar o melhor agente eluente a ser utilizado e a sua concentração. Utilizaram-se três eluentes distintos: um ácido $(\mathrm{HCl})$, um básico $(\mathrm{NaOH})$ e um sal $(\mathrm{NaCl})$; com o ácido e a base testaram-se três concentrações: 0,01 mol.L $\mathrm{L}^{-1}, 0,1 \mathrm{~mol} . \mathrm{L}^{-1} \mathrm{e} 1 \mathrm{~mol} . \mathrm{L}^{-1}$, e com o sal, apenas a concentração de 1 mol.L $\mathrm{L}^{-1}$. O ensaio foi realizado em triplicata nas mesmas condições da etapa de adsorção: sistema batelada à temperatura de $30{ }^{\circ} \mathrm{C}$ com velocidade de agitação de $100 \mathrm{rpm}$, utilizando $0,7 \mathrm{~g}$ de massa seca do adsorvente e $50 \mathrm{~mL}$ de agente eluente. Após 24 horas de agitação, realizou-se a leitura das absorbâncias das amostras em um espectrofotômetro (Shimadzu UV1800) no comprimento de onda de $610 \mathrm{~nm}$. A eficiência de dessorção (\%) foi calculada empregando a equação (2) buscando-se determinar o melhor agente eluente a ser utilizado e a sua concentração. Três eluentes distintos foram avaliados: um ácido $(\mathrm{HCl})$, um básico $(\mathrm{NaOH})$ e um sal $(\mathrm{NaCl})$.

$$
\% \text { Eficiência de Dessorção }=100-\frac{\left(C_{\text {adsorvente }}^{\text {inicial }}-C_{\text {solução }}^{\text {final }}\right)}{C_{\text {adsicial }}^{\text {isvente }}} \cdot 100
$$

\subsection{Cinética de dessorção do corante reativo Azul 5G}

Para realizar a cinética de dessorção do corante utilizou-se o melhor agente eluente, $\mathrm{NaOH} 1$ mol.L $\mathrm{L}^{-1}$. Nestes ensaios foi avaliada a influência da temperatura e determinado o tempo de contato necessário para a dessorção do corante pelo bagaço de malte. $\mathrm{O}$ experimento foi realizado em três temperaturas distintas, sendo $30{ }^{\circ} \mathrm{C}, 40{ }^{\circ} \mathrm{C}$ e $50{ }^{\circ} \mathrm{C}$ e nas mesmas condições descritas para a adsorção: rotação de $100 \mathrm{rpm}, 0,7 \mathrm{~g}$ de massa seca do adsorvente e $50 \mathrm{~mL}$ de solução do agente eluente. Na cinética de dessorção foram retiradas amostras em intervalos de tempos pré-estabelecidos, entre $5 \mathrm{~min}$ e $12 \mathrm{~h}$. Ao separar o adsorvente do eluente foi quantificada a concentração de corante dessorvido presente na fase fluida.

\section{RESULTADOS E DISCUSSÕES}

Os resultados obtidos para o experimento de saturação do bagaço de malte são apresentados na Tabela 1.

Tabela 1 - Saturação do bagaço de malte com corante reativo 5G.

Concentração (mg.L $\left.\mathrm{L}^{-1}\right) \quad$ Remoção (\%) $\quad$ qeq $\left(\mathrm{mg} . \mathrm{g}^{-1}\right)$


Três agentes eluentes distintos foram testados, um ácido, um básico e um sal, com diferentes concentrações. O agente eluente ácido e o sal apresentaram capacidade de dessorção do corante nula, independente da concentração da solução eluente avaliada. Os resultados obtidos para o eluente básico estão demonstrados na Tabela 2.

Tabela 2- Eficiência da dessorção do corante reativo azul 5G utilizando solução de $\mathrm{NaOH}$ com diferentes concentrações (100 rpm, $30^{\circ} \mathrm{C}, 14$ g.L $\mathrm{L}^{-1}, 50 \mathrm{~mL}, 24$ horas).

\begin{tabular}{|c|c|}
\hline Eluente & Eficiência de dessorção (\%) \\
\hline $\mathrm{NaOH} 0,01 \mathrm{~mol}^{-\mathrm{L}^{-1}}$ & 24,60 \\
\hline $\mathrm{NaOH} 0,1 \mathrm{~mol} . \mathrm{L}^{-1}$ & 32,60 \\
\hline $\mathrm{NaOH} 1$ mol.L-1 & 38,54 \\
\hline
\end{tabular}

Analisando o comportamento das diferentes concentrações para o agente eluente básico $\mathrm{NaOH}$, conclui-se que a solução de maior concentração $\left(1\right.$ mol.L $\left.\mathrm{L}^{-1}\right)$ apresentou o melhor percentual de dessorção $(38,54$ \%). Em termos industriais se faz necessário o estudo de ciclos de adsorção/dessorção do corante para que se possa obter maior reutilização do material adsorvente no processo. No entanto, o intuito, nesta etapa, era apenas avaliar a capacidade de dessorção do corante.

Em virtude desses resultados obtidos, os ensaios cinéticos de dessorção foram realizados empregando-se solução de $\mathrm{NaOH} 1$ mol.L-1 como agente eluente.

No ensaio cinético, o adsorvente bagaço de malte saturado com o corante reativo azul $5 \mathrm{G}$ foi colocado em contato com o agente eluente selecionado, sendo os resultados para as temperaturas de $30^{\circ} \mathrm{C}, 40^{\circ} \mathrm{C}$ e $50^{\circ} \mathrm{C}$ apresentados na Figura 1.

Figura 1 - Eficiência de dessorção do corante reativo azul 5G em função do tempo em diferentes temperaturas (100 rpm, 14 g. $\mathrm{L}^{-1}$ dosagem de adsorvente, $50 \mathrm{~mL}$ de solução eluente, $12 \mathrm{~h})$ 


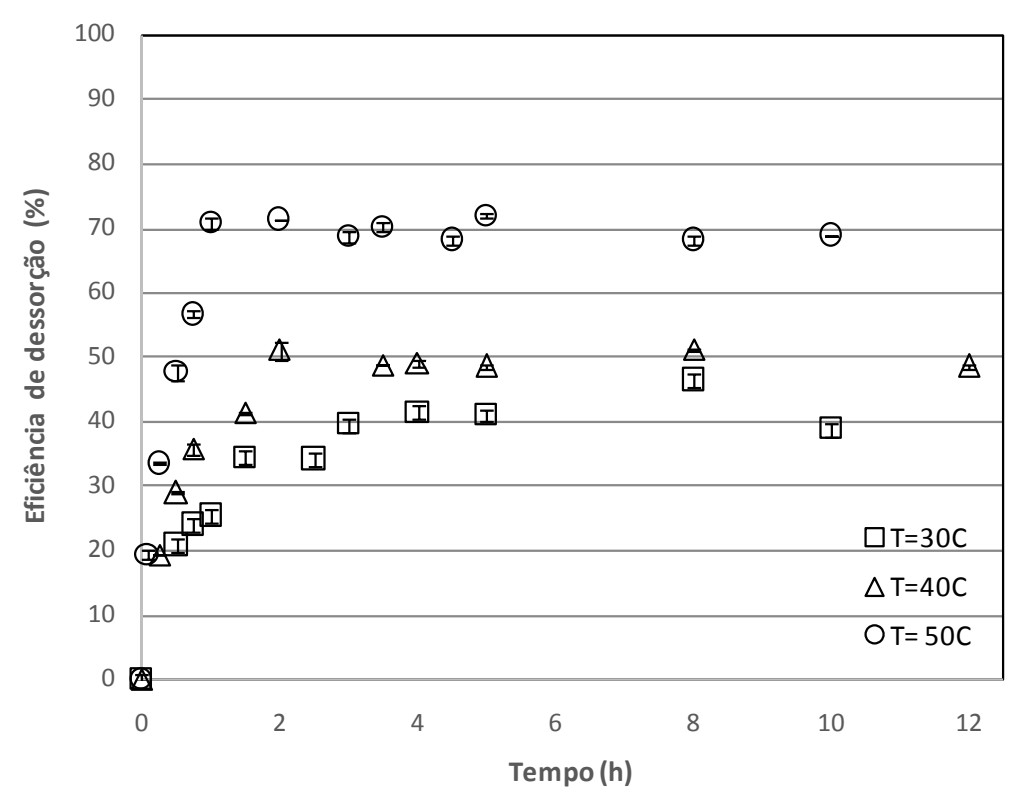

Na Figura 1 pode-se observar que a eficiência de dessorção do corante azul 5G a partir do bagaço de malte foi influenciada pela variável temperatura. O tempo de contato necessário para o sistema adsorvente - eluente atingir o equilíbrio na dessorção foi de 3 horas, 2 horas e 1 hora para as temperaturas de $30^{\circ} \mathrm{C}, 40^{\circ} \mathrm{C}$ e $50^{\circ} \mathrm{C}$, respectivamente.

Para a temperatura de $50{ }^{\circ} \mathrm{C}$ a quantidade de corante dessorvido no equilíbrio foi de $5,81 \mathrm{mg} \cdot \mathrm{g}^{-1}$, correspondendo a uma eficiência de $70,8 \%$, enquanto que para a temperatura de $30{ }^{\circ} \mathrm{C}$ esse valor foi de $3,36 \mathrm{mg} \cdot \mathrm{g}^{-1}$, eficiência de $39,5 \%$. Na temperatura de $40{ }^{\circ} \mathrm{C}$ obteve-se uma eficiência de dessorção de 4,34 mg.g-1 $(51,1 \%)$.

A partir dos resultados obtidos para a cinética e a eficiência de dessorção do corante azul $5 \mathrm{G}$ é possível constatar que o processo é favorecido em maior temperatura $\left(50{ }^{\circ} \mathrm{C}\right)$, apresentando concomitantemente menor tempo para o sistema estabelecer o equilíbrio na dessorção.

Fiorentin (2009) estudou a dessorção do corante reativo azul 5G em bagaço de laranja e concluiu que, em pH 10, houve uma elevada redução do corante no bagaço, sendo cerca de $97 \%$.

Menezes (2010) realizou um estudo da dessorção do bagaço de maracujá e concluiu que o pH 12 foi o que obteve a melhor porcentagem de remoção, cerca de $78 \%$, sendo que para pHs de 2 a 10 não houve remoções satisfatórias.

Gobi (2014) testou as temperaturas de $25{ }^{\circ} \mathrm{C}, 35^{\circ} \mathrm{C}$ e $45^{\circ} \mathrm{C}$ em um teste de cinética para a dessorção da casca da soja no mesmo corante estudado neste trabalho. Sendo assim, a autora observou que o equilíbrio foi atingido, para as três temperaturas, aproximadamente em 100 minutos, obtendo uma eficiência de dessorção de 59,23 \%.

Comparando os resultados obtidos com o trabalho realizado por Gobi (2014), citado anteriormente, o bagaço de malte apresenta resultados mais favoráveis que a casca de soja, 
estudada pela autora. No entanto, ainda não possui eficiência superior ao bagaço de laranja e ao bagaço de maracujá, estudados por Fiorentin (2009) e Menezes (2010), já mencionados.

\section{CONCLUSÃO}

Analisando a cinética de dessorção realizada nas temperaturas de $30{ }^{\circ} \mathrm{C}, 40{ }^{\circ} \mathrm{C}$ e $50{ }^{\circ} \mathrm{C}$, observou-se que a eficiência de dessorção foi crescente, sendo que na temperatura de $50{ }^{\circ} \mathrm{C}$ a eficiência de dessorção foi superior, cerca de 70,8 \% em uma hora de contato. Além disso, o tempo de equilíbrio foi de 3 horas, 2 horas e 1 hora, para as temperaturas de $30{ }^{\circ} \mathrm{C}, 40{ }^{\circ} \mathrm{C}$ e $50{ }^{\circ} \mathrm{C}$, respectivamente.

Diante dos resultados apresentados observa-se que o bagaço de malte é um bom adsorvente quando estudado com o corante reativo azul 5G. O processo mostrou-se vantajoso, uma vez que se trata da reutilização de um subproduto industrial derivado do processo de filtração da cerveja.

\section{REFERÊNCIAS}

ALMEIDA, E.; ASSALIN, M. R.; ROSA, M. A. Tratamento de efluentes industriais por processos oxidativos na presença de ozônio. Química Nova, v. 27, p. 819, 2004.

BUMPUS, J. A.; AUST, S. D. Biodegradation of environmental pollutants by White-rot fungus Phanerochaete chrysosporium Bioassays, v. 6, p. 170, 1987.

CEGARRA, J. Biotecnologia aplicada aos processos de química têxtil. R. Quim Têxtil v. 58, p. 5,2000 .

CERVBRASIL, Associação Brasileira da Indústria da Cerveja DBR INTERATIVA, 2015.

Disponível em: < http://cervbrasil.org.br/>. Acesso em: 20 jan 2015.

FIORENTIN, L. D. Remoção de Corante de Efluentes da Industria Têxtil Utilizando Processos com Membranas e Adsorção em Bagaço de Laranja. Tese de Doutorado em Engenharia Quimica, Universidade Estadual de Maringá, Maringá, 163p. 2009.

FREITAS, I. C. V. Adsorção e dessorção de metais no solo e coeficientes de isotermas de Freundlich e Langmuir. Agropecuária Técnica, Areia, PB. v. 31, 2010.

GOBI, F. P.; GONÇALVES, G.C.; KLEN, M.R.F.; JUCHEN, P.T.; HONORIO, J.F.; VEIT, M.T. Dessorção do corante comercial azul $5 \mathrm{~g}$ a partir do adsorvente casca de soja. $X$ Encontro Brasileiro sobre Adsorção, Guarujá, SP, 2014.

GUARATINI, C.C.I.; ZANONI, M.V.B. Corantes têxteis, R. Quím Nova, p. 71-78, 2000.

MENEZES, M. L. Remoção do corante reativo azul 5G a partir de soluções aquosas utilizando o bagaço do maracujá amarelo como adsorvente. Dissertação de Mestrado do curso de Engenharia Química da Universidade Estadual de Maringá, UEM, Maringá, Paraná, 2010. 
PEARCE, C. I., LLOYD, J. R., GUTHRIE, J. T. The removal of colour from textile wastewater using whole bacterial cells:a review. Dyes Pigments v. 58, 2003.

ROYER, B. Remoção de corantes têxteis utilizando casca de semente de Araucária angustifólia como biossorvente. Dissertação de Mestrado do curso de Química da Universidade Federal do Rio Grande do Sul, Porto Alegre, 2008.

SANTOS, M. S.; RIBEIRO, F. M. Cervejas e Refrigerantes, CETESB, São Paulo. 58p. 2005.

TEXPAL, "Ficha de informação de segurança de produtos químicos - FISPQ". Revisão A., 2008. 